\title{
CONSIDERAÇÕES COMPARADAS SOBRE A FORMA CIRCULAR DO TEMPO MÍTICO E SUAS RELAÇÕES COM O RITO
}

\author{
COMPARATIVE CONSIDERATIONS ON THE CIRCULAR \\ FORM OF THE MYTHIC TIME AND ITS RELATIONS \\ WITH THE RIT
}

\author{
José D’Assunção Barros*
}

\begin{abstract}
Resumo: Busca-se examinar o aspecto circular presente nas antigas concepções míticas sobre a forma do Tempo, exemplificando com alguns dos modelos míticos de representação circular do Tempo que aparecem nas mitologias hindu, grega, jainista e havaiana. O modelo circular do tempo mítico é contrastado, em seguida, com o padrão linear de tempo que é introduzido com a perspectiva cristã. $O$ artigo também examina a relação entre mito e rito, que introduz uma forma binária no tempo circular proposto em alguns dos modelos míticos de decadência da humanidade.
\end{abstract}

Palavras-chave: Tempo. Narrativa. Mito.

Abstract: This article aims to examine the circular aspect included in some of the
ancients mythic conceptions about the form of Time, exemplifying with some of mythic
patterns of circular representation of Time that appear in the mythologies hinduist,
jainist, greek and Hawaiian. The circular pattern of the mythic time is contrasted, in the
sequence, with the linear pattern of Time introduced by Christian perspective. The article
examines also the relation between myth and rite, which introduces a binary form in
the circular time proposed by some of the mythic patterns of decadence of humanity.

Keywords: Time. Narrative. Myth.

* Professor-adjunto na Universidade Federal Rural do Rio de Janeiro, nos cursos de Graduação e Pós-Graduação em História. Professor colaborador no Programa de PósGraduação em História Comparada da Universidade Federal do Rio de Janeiro.

E-mail: jose.d.assun@globomail.com 
Diversas formas de entender ou representar o Tempo têm sido elaboradas no decorrer da história. Neste artigo, examinaremos principalmente o modelo circular de tempo antigo Tempo Mítico, a partir do estudo de alguns casos com vistas a uma apreensão comparativa, considerando o tempo mítico elaborado em algumas das antigas civilizações e também em sociedades tribais que ainda existem nos dias de hoje. Uma importância especial será atribuída à relação entre Mito e Rito, examinando como a segundo instância pode favorecer o preenchimento da circularidade temporal em certos mitos, particularmente nos mitos de decadência humana. A ideia de decadência humana não é apresentada como conceito, mas sim como uma representação que aparece em diversas culturas míticas situando o gradual ou brusco declínio, através da narrativa mítica, de uma humanidade vista pelos elaboradores do mito como de tipo superior para uma humanidade vista como de tipo inferior ao primeiro, seja por maior fragilidade ou valores morais. Além disso, apenas para favorecer uma compreensão mais clara deste modelo circular de tempo, será também estabelecido um contraste em relação ao modelo linear de tempo que é introduzido pelo Cristianismo. Para entender como a circularidade está também presente em algumas das representações míticas de decadência da humanidade, discutiremos ainda a perspectiva do "rito", que reintroduz a possibilidade de volta às origens nos modelos míticos da decadência da história humana.

Começaremos por uma indagação. Como funcionava, ou ainda funciona em diversas sociedades, o Tempo Mítico? Consideremos a Figura 1:

Figura 1 - O Tempo Cíclico: um exemplo binário

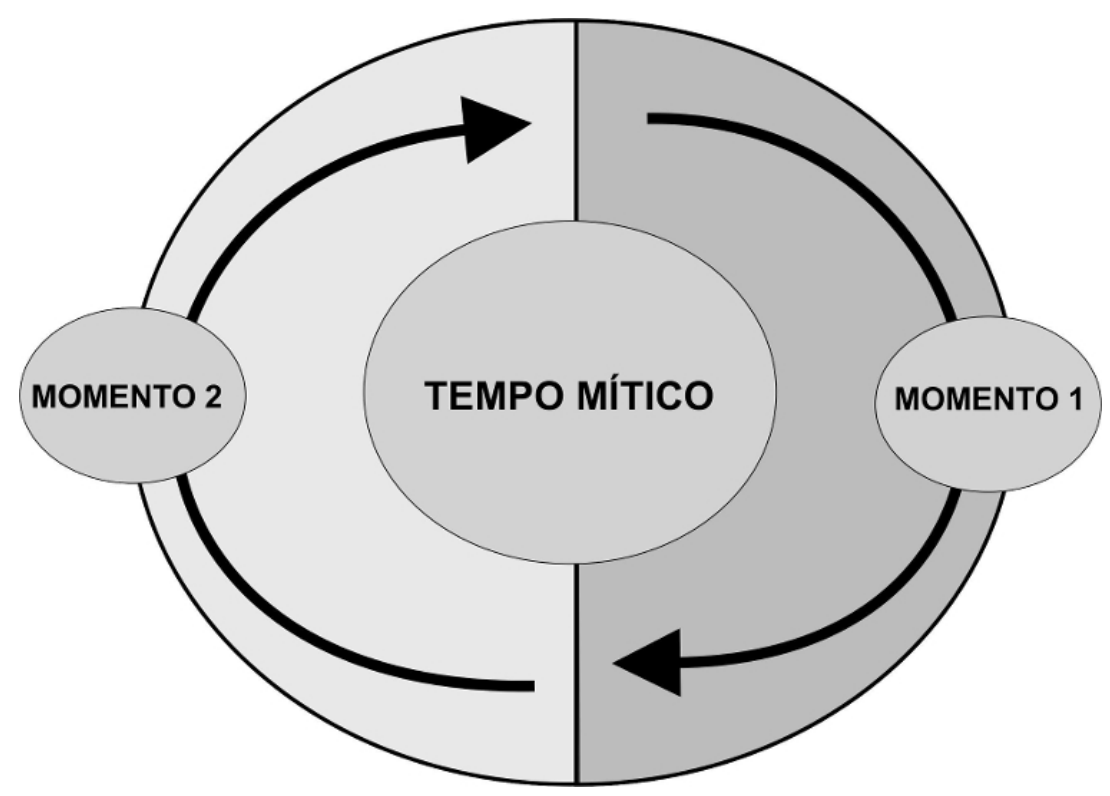

Fonte: Figura elaborada pelo autor. 
O Tempo Mítico, de modo geral, apresenta uma estrutura circular. Além disto, trata-se de um tempo reversível - se não através do próprio mito, que realiza o retorno em sua própria narrativa ou repetição cíclica, ao menos através do "rito", que corresponde a um retorno ritual às origens, conforme veremos mais adiante. A passagem do tempo e o seu ritmo também são bem distintos do que se dará com o tempo linear, medido cronologicamente. De fato, tal como assinala Jean-Pierre Vernant, com o Mito não se tem propriamente uma cronologia, mas sim uma "genealogia".

O padrão circular acima representado, alternando dois momentos, é apenas exemplificativo. Há mitos que articulam três, quatro, doze, ou mais momentos em sua narrativa cíclica. O ciclo natural das quatro estações, por exemplo, pode dar sustentação a uma narrativa mítica, ou também as fases da lua. Uma observação sistemática do céu em sociedades antigas como a dos maias ou astecas podia levar à percepção do retorno regular de determinado certo corpo celeste, tal como a reaparição de um cometa a grandes intervalos de tempo, e daí se originar uma narrativa mítica menos ou mais complexa. Um padrão bastante simples podia se inspirar na alternância natural entre o Dia e a Noite, gerando um esquema binário, como o acima representado. De igual maneira, outros modelos de movimento binário extraídos da natureza podem inspirar mitos subdivididos em dois momentos, como é o caso do vai e vem das águas do oceano, ou ainda o duplo movimento de inspiração e expiração dos seres vivos.

\section{O TEMPO BINÁRIO DA RESPIRAÇÃO DE BRAHMA}

Sobre a última matriz que acima evocamos - o tempo circular fundado em movimentos binários inspirados na Natureza - está construída a cosmogonia hindu da "respiração de Brahma", que apresenta a ideia de que, quando o Deus expira, o Universo se manifesta, e, quando inspira, o universo se retrai e retorna ao não-manifesto. ${ }^{2}$ A matriz da respiração, neste caso, também pode ser articulada à matriz da oposição entre as duas fases do dia, gerando as imagens do "dia de Brahma" e da "noite de Brahma", respectivamente relacionadas à expiração e inspiração do deus. Na primeira metade do kalpa (o "dia de Brahma" completo), o universo é criado; a certa altura, é destruído pelo Deus Shiva para que se inicie a "noite de Brahma". Aqui, a narrativa mítica circular, articulada em dois momentos, projeta-se diretamente sobre o alfa e o ômega, sobre a questão primeira e última: a da própria criação e destruição (renovação) do Universo. ${ }^{3}$

Na verdade, o Rig Veda - livro sagrado extremamente complexo que teria sido produzido na Índia durante o século XX a.C. ${ }^{4}$ - apresenta pelo menos quatro grandes cosmogonias referentes à criação do Universo. ${ }^{5}$ Uma das 
sequências mais simples é aquela que aparece em inúmeras outras mitologias que têm na água o seu elemento primordial. (1) Hiranyagarbha (o embrião dourado) paira sobre as águas, e a certo momento incorpora estas mesmas águas, fecundando-as. Isto produz o nascimento de Agni (deus do fogo), gerando-se em seguida o universo a partir da interação entre estes dois princípios (água e fogo). O fundo deste mito também é circular, pois tudo procede da água e a ela retorna. Aqui somos levados a pensar também na cosmogonia filosófica de Tales de Mileto (624-556 a.C), filósofo grego pré-socrático que afirmava que a água é a origem de todas as coisas e também a matéria para a qual tudo retorna, constituindo-se na verdadeira fonte do movimento e da vida no universo. A água, também aqui, é apresentada como um elemento divino, e Deus corresponderia à inteligência que tudo faz a partir da água. ${ }^{6}$

Outra sequência mítica (2) é trazida pelo mais famoso hino do Rig Veda. No princípio, não havia nem homens nem deuses. A única coisa que existia era um impulso, sem qualquer respiração: Brahma, que tinha derivado do calor. Deste gérmen em potencial desenvolveu-se o desejo, que correspondeu à primeira semente do conhecimento. A primeira semente dividiu-se então em uma "elevação" e em um "ponto baixo", gerando um princípio masculino e um princípio feminino. ${ }^{7}$ Nesta narrativa mítica, Brahma precede o universo e cria o mundo derivando-se do seu próprio ser. $\mathrm{O}$ padrão ajusta-se à já mencionada estrutura binária da respiração bramânica. ${ }^{8}$ Os Vedas ainda trazem uma terceira ordem mítica, que corresponde ao (3) mito da separação do céu e da terra, no qual ocorre uma violenta divisão da totalidade primordial com a finalidade de criar o mundo. Em seguida ao caos originado por essa separação entre Céu e Terra, efetiva-se a Criação de um universo já diferenciado através da ação de um ser divino, uma espécie de artesão universal chamado Visvakarman, que dá forma ao mundo como faria um artífice. Esta narrativa mítica é apresentada pelos poetas védicos como tema relacionado à ideia da "criação-sacrifício", e podemos encontrar versões da mesma em outras sociedades e culturas.

Por fim, outra sequência cosmogônica similar (4) aparece em um dos hinos do Rig Veda - o Purusasukta - e também aborda o tema do desmembramento de uma totalidade primordial, mas agora girando em torno de um gigantesco ser antropomórfico e andrógino chamado Purusa, e que corresponderia à totalidade primordial. A Criação é resultado de um "sacrifício cósmico" encaminhado pelos deuses, que resolvem desmembrá-lo para gerar não apenas a Natureza, como também a própria sociedade humana e mesmo novos deuses (o que reforça o caráter cíclico do mito): "Sua boca tornou-se Brahma; o Guerreiro foi o produto de seus braços; suas coxas deram origem aos artesãos; de seus pés nasceram os servos. Sua cabeça transformou-se no céu, seus pés na terra, a Lua resultou de seu conhecimento, o sol de seu olhar, a sua boca [já vertida em Brahma] e agora transformada em Indra e Agnie, produziu o vento da respiração [cósmica]". Este mito, que ilustra um padrão de 
narrativa cosmogônica no qual a Criação é produzida pelo sacrifício de um ser divino de características antropomórficas, também pode se articular ao mito da expiração e inspiração Bramânica (já que o mito contém dentro de si a origem do próprio Brahma e de sua respiração a partir da Boca do ser primordial).

\section{O MUNDO COMO PRODUTO DA ATIVIDADE ONÍRICA DE UM DEUS}

Os labirintos da mitologia indiana - inaugurados pelo Bramanismo, mas depois desdobrados no Budismo, no Janaísmo, e posteriormente em formas diversas do Hinduísmo - são extremamente complexos. Em uma das mais conhecidas versões, Brahma - deus de quatro cabeças que olha para todas as direções e que está sentado sobre uma flor de lótus - brotou do umbigo de Vishnu, o Deus que, dormindo, sonha o universo e tudo o que há nele. Nesta versão, Brahma é quem organiza os mundos (correspondendo à força criadora ativa), mas não é quem os cria primordialmente, já que os vários mundos são gerados pelos sonhos de Vishnu. ${ }^{9}$

Em vista de seu poder de criar e recriar os mundos através de sua atividade onírica, Vishnu - "aquele que está em tudo" - torna-se a representação do equilíbrio, sendo o responsável pela sustentação, proteção e manutenção do universo. ${ }^{10} \mathrm{O}$ ciclo de fluxo e refluxo, nesta versão, origina-se de Vishnu. Quando Vishnu expira, universos inteiros saem de seus poros, manifestamse através da 'ação criadora ativa' de Brahma e são habitados; e a cada final dos tempos, no momento da inspiração de Vishnu, serão novamente sugados pelos seus poros. Este é também o momento em que Brahma se recolhe para dormir, e no qual Shiva se põe em atividade destruindo tudo pelo fogo. Shiva é o dançarino cósmico, deus da destruição que a tudo incinera com o abrasivo calor do fogo da renovação, nos instantes em que abre seu terceiro olho. Depois que o universo é destruído por Shiva, há como que um momento fora do tempo cíclico da respiração, no qual Vishnu se encontra dormindo sem sonhos e flutuando sobre o oceano primordial. Depois deste instante, quando o próximo universo está para ser recriado, reinicia-se a respiração onírica e reaparece Brahma do umbigo de Vishnu para criar tudo mais uma vez.

Ao mesmo tempo em que sonha novos mundos, Vishnu é também capaz de penetrar em todos os átomos de cada um dos universos gerados por sua atividade onírica, bem como no coração de todas as criaturas vivas que os habitam, e em todos e cada um destes lugares permanece como observador imperturbável. Por outro lado, há ainda a figura de Durga - mãe do universo que representa o poder do sono que age sobre Vishnu no momento do interciclo entre a Criação e a Destruição. ${ }^{11}$ Pode-se dizer que a posição de Brahma é um pouco ambígua nesta versão da mitologia hindu, pois depois de ter criado o 
mundo a partir da respiração de Vishnu, deus do qual ele mesmo saíra, parece se esgotar por um instante a sua função (ao menos nos limites dos mundos já criados, se considerarmos que Brahma continua criando mundos durante toda a parte do "dia de Brahma" que corresponde à expiração de Vishnu). Assim mesmo, há aqui uma intrincada dialética a considerar, pois no panteão primordial dos deuses hindus há três aspectos manifestos: o Criador (Brahma), o Preservador (Vishnu) e o Destruidor (Shiva). ${ }^{12}$ Além disto, Brahma reaparece mais uma vez entregando aos seres humanos os Vedas - livros que já trazia em suas mãos no momento mesmo em que brotara do umbigo de Vishnu. ${ }^{13}$

\section{O TEMPO CÍCLICO DOS GREGOS E A SEPARAÇÃO PRIMORDIAL ENTRE O CÉU E A TERRA}

O mito da separação violenta entre o Céu e a Terra, que apontamos como uma das narrativas míticas incluídas nos Vedas com relação à criação do mundo, também reaparece em culturas várias. Marshall Sahlins o encontrou entre os maori. O mito de criação do mundo deste povo parte da união inicial entre o Céu (ranci) e a Terra (papa). Da união entre os espaços elementais masculinos e femininos teriam nascido os diversos deuses, que depois separaram o Céu e a Terra em âmbitos distintos. Surge posteriormente um deus chamado Tane que molda uma mulher com a matéria extraída da própria Terra, para depois inseminá-la e dar origem à Humanidade. ${ }^{14}$ Todos os homens, saídos da própria terra, a ela retornam inevitavelmente, reatualizando eternamente o mesmo ciclo.

Os mitos cíclicos, conforme documentam as pesquisas etnográficas e as fontes míticas que nos foram legadas de civilizações já históricas através da escrita, aparecem de inúmeras maneiras tanto nas diversas mitologias das grandes civilizações como em culturas mais localizadas. Entre os gregos, Gaia (a Terra) dá a luz a Urano (o Céu), que depois irá fertilizá-la. Cronos (Saturno), filho de ambos e o primeiro dos Titãs, irá romper a conjugação entre o Céu e a Terra ao castrar o próprio pai, a pedido da própria mãe, configurando um "ato edípico de substituição", para utilizar uma expressão de Marshall Sahlins. ${ }^{15}$ A partir daí inicia-se a segunda geração de deuses gregos, presidida por Cronos. Durante o reinado de Cronos, a humanidade teria vivido a sua "Idade de Ouro", conforme o padrão mítico de eras progressivamente decaídas que comentaremos mais adiante. Ao casar-se com sua irmã Réia, Cronos teve três filhas e três filhos (Hades, Poseidon e Zeus). Uma vez que - em vista de seu próprio crime patricida, e também por temor a uma maldição que havia sido rogada por Urano ao profetizar que um dia Cronos também seria destronado por seu próprio filho - o deus do Tempo desenvolvera o hábito de devorar todos os seus filhos homens ao nascerem. Mas Réia consegue enganá-lo por ocasião do nascimento de Zeus (Júpiter), oferecendo-lhe uma pedra enrolada em um 
pano, que Cronos engoliu sem perceber a troca. Mais tarde, Zeus voltará para se vingar de Cronos, que também é levado a beber uma poção mágica que o faz vomitar os outros dois filhos (já adultos) que um dia tinha devorado (Hades e Poseidon). A partir daí, depois de vencer uma guerra de cem anos e de banir os tios Titãs para o Tártaro e acorrentar Cronos no mundo subterrâneo, Zeus torna-se senhor do Olimpo e líder da terceira geração de deuses, enquanto seus irmãos Hades e Poseidon irão se tornar respectivamente os senhores do mundo dos mortos e dos mares.

As três sequências constituem ciclos: Uranos, que representa a geração inicial de deuses gregos, é destronado pelo filho Cronos, que será por fim destronado por Zeus. ${ }^{16}$ Também se articula à narrativa dos deuses gregos ${ }^{17}$ um mito à parte que se refere à Humanidade, e cujo padrão reaparecerá de modos variados em outras culturas: trata-se de um singular padrão mítico que encaminha uma narrativa sobre diversas eras que vão sucessivamente se degradando, e que muito habitualmente corresponde a uma perspectiva pessimista destinada a explicar a deficiente natureza humana.

No caso da mitologia grega, a degradação humana encontra seu mito maior na Teogonia de Hesíodo, um poeta que viveu em fins do século VIII a.C. ${ }^{18}$ Depois de descrever a já discutida narrativa relativa às várias gerações de deuses gregos, Hesíodo interpola em sua Teogonia os célebres episódios de Prometeu e de Pandora, que irão precisamente justificar a condição humana. Prometeu havia roubado o fogo divino para dá-lo aos homens, e com isso atrai a ira de Zeus, terminando por ser condenado à tortura cíclica de ter o fígado eternamente devorado por uma ave. Para os mortais, o castigo foi ardiloso: é criado um ser à imagem e semelhança das deusas imortais que irá oferecer aos homens um presente em nome dos deuses olímpicos. Epimeteu, irmão de Prometeu, recebe o presente e, ao abrir a "caixa de Pandora", deixa escapar todos os males do mundo, conseguindo aprisionar apenas a Esperança.

Quando a caixa de Pandora se abre, inicia-se a decadência humana. A partir daí, Hesíodo registra quatro eras da humanidade que se degradam sucessivamente: a Idade do Ouro ficaria para trás, e se iniciam, em seguida, a Idade de Prata, a Idade de Bronze, a Idade de Ferro. Entre a Idade do Bronze e a Idade do Ferro, Hesíodo na verdade encaixa mais uma era, a "Idade dos Heróis". Mas isto não altera muito a ideia geral deste mito, que procura essencialmente retratar a progressiva degradação da humanidade através de sucessivas eras. 
Figura 2 - Um mito de degradação humana

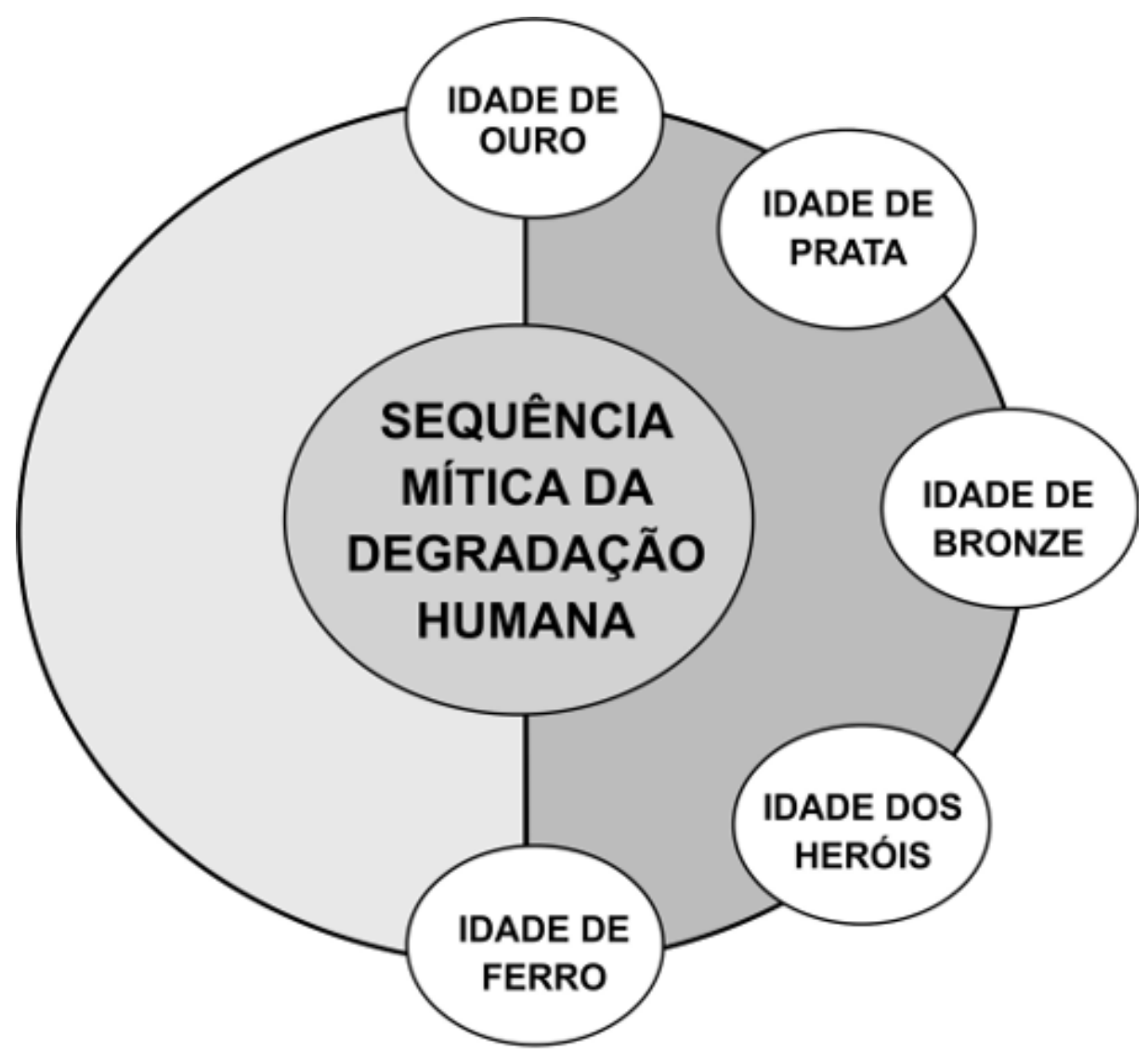

Fonte: Figura elaborada pelo autor.

\section{O TEMPO MÍTICO NA MITOLOGIA JAINÍSTA}

O padrão mítico apresentado por Hesíodo não é um caso isolado na história do pensamento mitológico. Muitas outras sociedades produziram narrativas similares, em geral para explicar as evidentes deficiências humanas. É assim que o imenso repertório de mitos nas várias sociedades e civilizações oferece muitas variações que envolvem sequências míticas de degradação da humanidade. Podemos citar o interessante exemplo do Jainismo, que é uma das mais antigas religiões indianas, ao lado do Budismo e do Hinduísmo. ${ }^{19}$ Aqui se apresenta uma imagem bastante peculiar do Tempo, descrito como um "giro cosmogônico" que inclui dentro de si a sequência da degradação humana. O que ocorre, porém, é que a 'série descendente de degradação' será contrabalançada por uma 'série ascendente' de recuperação da virtude, de modo que ao fim de tudo se constitui um círculo que se repete eternamente. ${ }^{20}$ 
Na mitologia jainista, o Tempo é representado por uma roda de doze raios (idades), sendo que seis idades constituem uma 'série descendente' (avasarpini) e seis idades constituem a 'série ascendente' (upsarpini).

\section{Figura 3 - $O$ tempo como uma roda de 12 raios,} na mitologia jainista

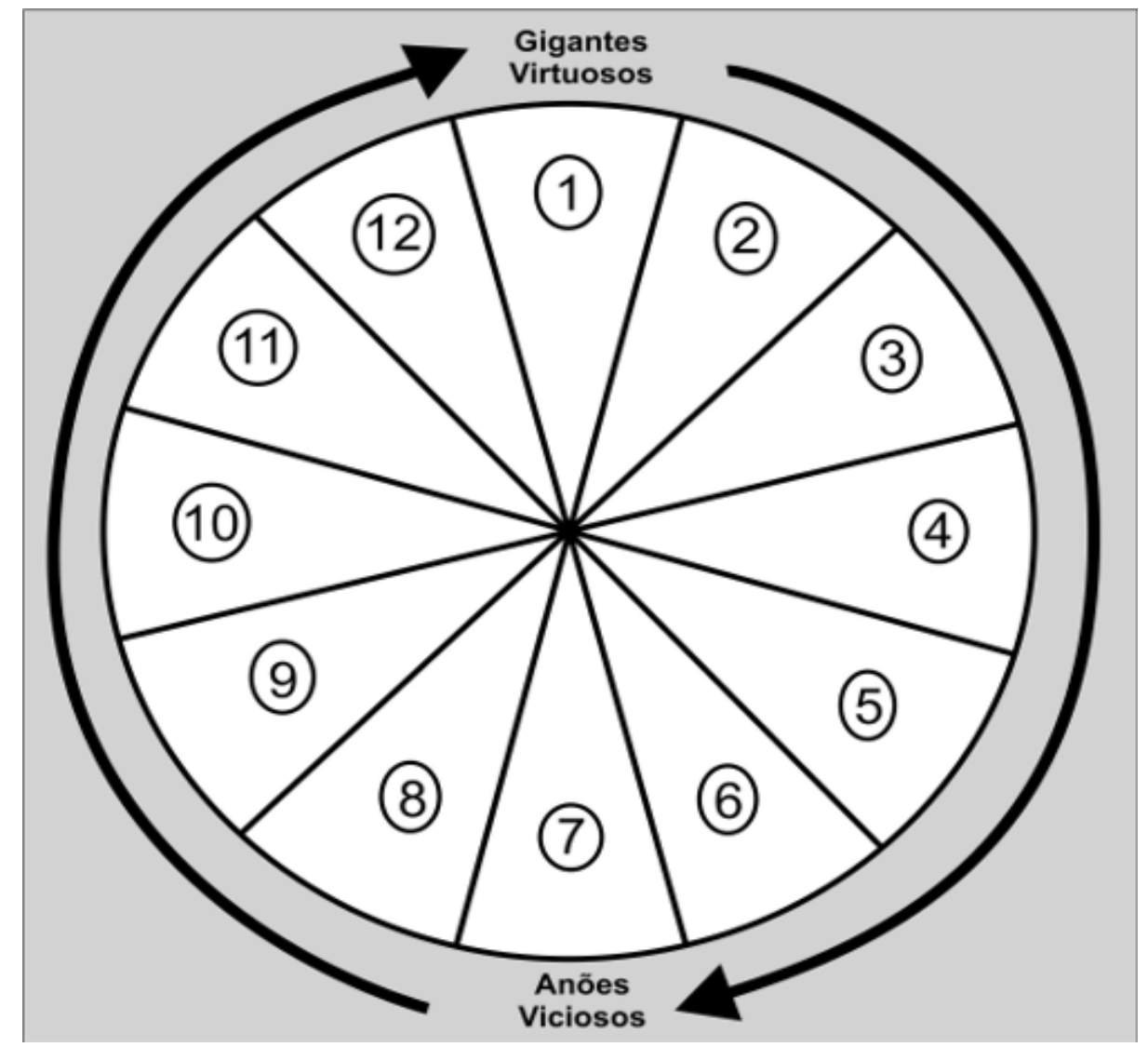

Fonte: Figura elaborada pelo autor

No modelo de degradação humana proposto pela mitologia jainista, o circuito descendente, no qual a felicidade começa a se misturar com a tristeza e a virtude com os vícios, corresponde à ocorrência de sucessivos decréscimos na estatura física e moral dos seres humanos, que de colossais gigantes geminados, plenos de virtudes, ao final da série descendente já terão se transformado em anões entregues a toda sorte de vícios e já sem nenhum resquício das virtudes primordiais. Mas então se iniciará, deste que é o ponto mais baixo possível da decadência humana, a série ascendente, que através de seis novas idades restituirá progressivamente aos seres humanos a sua estatura moral e física, levando-os de novo ao ponto de origem, no qual todos possuíam uma altura 
descomunal em relação ao padrão atual. Depois, o círculo reinicia, e assim ocorre indefinidamente através de imensos ciclos de tempo.

Além da diminuição na estatura e da degradação das virtudes, à medida que o Tempo avança pela série descendente também ocorreria uma gradual redução na duração da vida dos seres humanos. Na quinta idade da série descendente (no esquema, correspondente ao número "6"), a duração máxima da vida humana poderia chegar a 120 anos. Depois desta idade, que segundo os jainistas teria se iniciado em 522 a.C, irá se iniciar uma "idade de anões", na qual não apenas a altura máxima se restringiria a 50 centímetros, como também a duração da vida poderia chegar no máximo a 20 anos.

\section{O RITO COMO SOLUÇÃO PARA A RETOMADA CÍCLICA NOS MITOS DA DEGENERAÇÃO HUMANA}

O mito jainista da degradação humana faz parte do grupo de narrativas que, além da fase de degradação, incluem uma série ascendente de recuperação da virtude ou da bem-aventurança, de modo a contrabalançar a série descendente e negativa. Mas há também aquelas narrativas míticas, tal como foi o caso da sequência das quatro ou cinco eras de Hesíodo, que registram apenas a degradação, sem prever o retorno cosmogônico à situação primordial. Isto não impede, contudo, que a circularidade mítica possa ser alcançada através de outros artifícios. Há um poderoso elemento que pode reinstaurar desde sempre o equilíbrio, ou mesmo resgatar o homem da angústia da finitude, ao transportar o indivíduo humano (ou o grupo) ao tempo primordial: o recurso do rito.

O ritual é frequentemente concebido como um recurso capaz de assegurar uma "redenção na origem". Através do ritual - sob a forma da festa, do transe, dos cânticos, da sessão de cura, da narrativa - o indivíduo humano retorna às suas origens e reintegra-se ao Cosmos. Supera, portanto, a sua limitada natureza humana. ${ }^{21}$ Desta maneira, pode-se dizer que, também aqui, refaz-se o tempo cíclico. Através do ritual, o indivíduo pertencente a uma humanidade decaída encontra a sua redenção na origem: torna-se ele mesmo Deus. ${ }^{22}$ É também através do Rito que, em muitas sociedades ágrafas, $o$ indivíduo reencontra o ancestral da tribo, unindo-se a ele durante o ritual. O Ritual permite refazer a outra metade de um tempo cíclico, restabelecendo um equilíbrio perdido. Rito e Mito, portanto, se completam, estabelecendo uma unidade cíclica. 
Figura 4 - Um mito de idades decaídas e seu retorno ritual

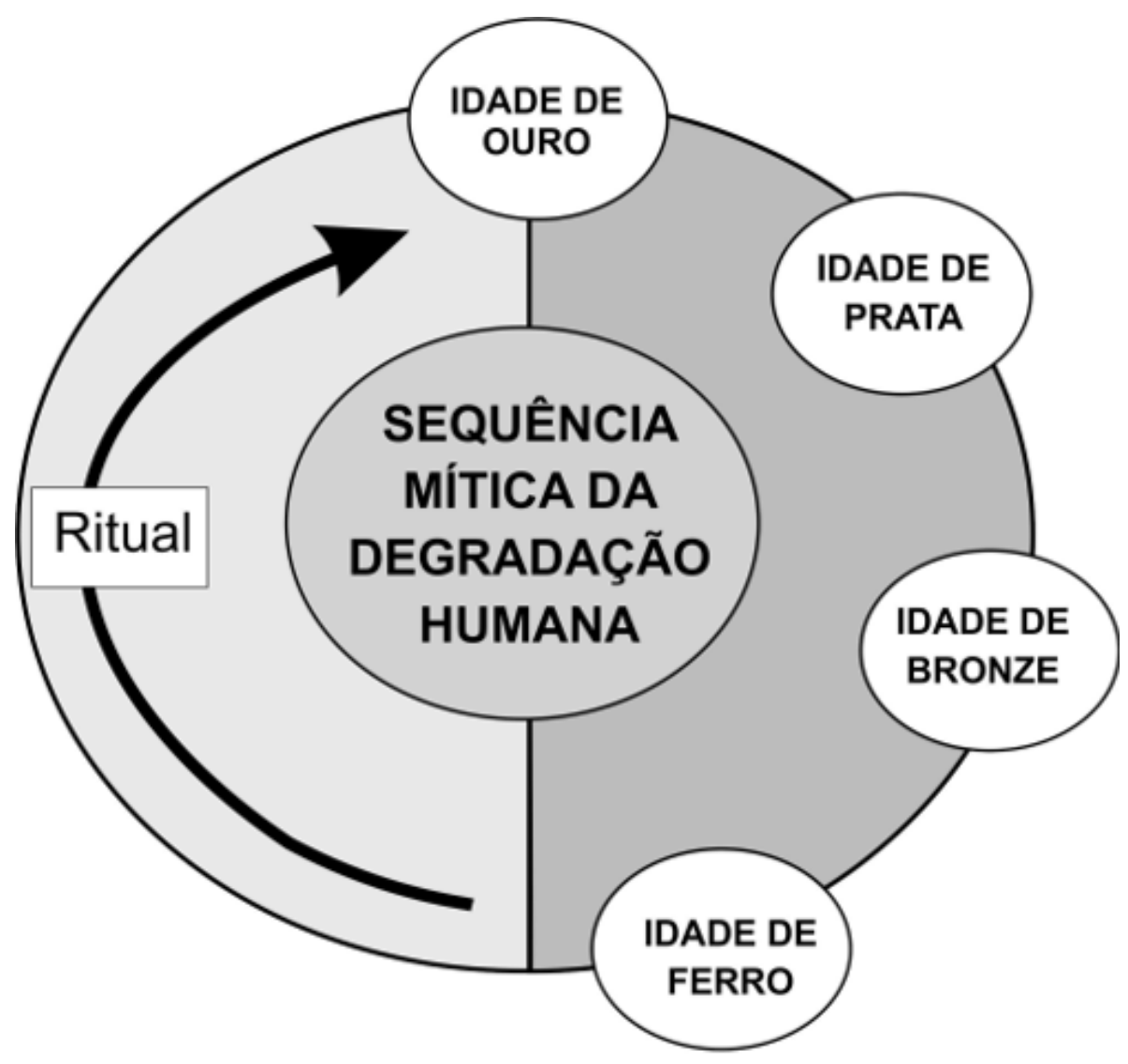

Fonte: Figura elaborada pelo autor.

Ao estudar os havaianos, o antropólogo Marshall Sahlins ${ }^{23}$ registra um interessante mito cíclico de caráter binário, que se reatualiza através da alternância ritual anual entre os deuses Lono e Kú. Lono faz a sua entrada com as chuvas de inverno, fertilizadoras da natureza, e institui um período produtivo e pacífico de quatro meses que, depois, será substituído pelo semicírculo de Kú. Para o pensamento mítico binário, não existe forçosamente simetria entre as duas metades de um ciclo. No mito em questão, a era de Lono corresponde a quatro meses do ano, e a era de Kú corresponde a oito meses, portanto a dois terços do ano. Isto não tem muita importância do ponto de vista do pensamento mítico. O que importa é que as duas metades se equiparam simbolicamente. Em termos de produção econômica, pois este mito liga-se também ao trabalho, o que assinala a passagem de Lono a Kú é a transição da pesca da cavala para a pesca do peixe-serra. Por outro lado, a sucessão de Lono por Kú corresponde a um mito de fundação bem conhecido dos havaianos. Lono é um Deus/Rei deposto. Kú, que lhe toma o poder, está associado a ritos sacrificiais. Na época em que o Havaí foi “descoberto" pelo Capitão Cook (1728-1779), em 1776, 
os rituais dirigidos a Kú eram praticados com sacrifícios humanos. O Capitão Cook, segundo Sahlins, teria sido assimilado pelos havaianos ao deus Lono, que no mito ancestral de fundação do Havaí havia sido deposto pelo deus Kú. Cook terminará tendo seu sacrifício ritual reivindicado pelo chefe havaiano, representante da linhagem do deus Kú. Desta maneira, uma intervenção histórica - esse evento externo que corresponde à chagada do Capitão Cook ao Havaí - termina por ser engolido pelo Mito, ao ser reincorporado no ciclo. O tempo judaico-cristão e sua linearidade

Tal como nos atesta Mircea Eliade em O Mito do Eterno Retorno $(1954)^{24}$, mas também Germano Pattaro em A Concepção Cristã do Tempo ${ }^{25}$, os hebreus, com seu "monoteísmo profético", estariam entre os primeiros seguidos pelos cristãos - a introduzir como concepção de ordenação cósmica um Tempo linear, irreversível, teleológico, através do qual os eventos datados e localizados desempenhariam um papel fundamental para as narrativas bíblicas. ${ }^{26}$ Ao substituir pela 'salvação futura' prevista nas profecias a 'redenção na origem' que era proposta pelos rituais e concepções míticas, e ao introduzir os eventos como peças chaves neste caminho linear em direção ao grande acontecimento do Juízo Final, os hebreus e cristãos preparam, tal como observam autores vários, a ideia de Tempo que logo permitiria o surgimento da História. ${ }^{27}$

Inventava-se com o judaísmo um novo tipo de História, orientada por uma linha única e voltada para o futuro, na qual a única macro-narrativa que tinha importância era a que se referia à trajetória do povo eleito. Contra o pano de fundo das pequenas histórias dos outros povos, os hebreus traziam a sua própria história a primeiro plano. Todos os eventos, mesmo os mais adversos, eram conclamados a participar de um plano que Deus tinha para um único povo, e até as mais ultrajantes derrotas perante os inimigos, como tão bem assinala Reinhart Koselleck no capítulo VI de Futuro Passado (1979), eram agora incorporadas como peças-chave neste enredo maior: nas narrativas judaicas estas derrotas tornavam-se penitência, "castigos que [os hebreus] foram capazes de suportar". ${ }^{28}$

Confirmando a tradição judaica recebida através do Velho Testamento, já é de fato um novo modelo de História - uma história universal com sentido único, e que aponta escatologicamente para um futuro no qual se eternizarão a salvação ou a condenação ${ }^{29}$ - aquele que é introduzido por Santo Agostinho em Cidade de Deus ${ }^{30}$, e que, passando na Idade Média por Gioachino da Fiore (1145-1202) $)^{31}$, chegará até o século XVII e a primeira metade do século XVIII

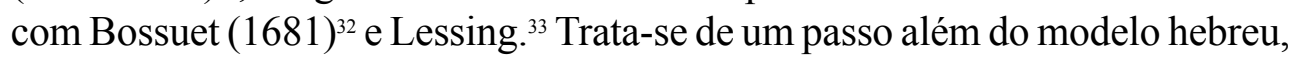
precisamente porque o modelo agostiniano refere-se a uma história de todo o gênero humano, e não mais a uma contraposição entre a história de um povo eleito e as histórias menores dos demais povos. ${ }^{34}$ De resto, esta História - que Santo Agostinho concebe em seis etapas por paralelismo com o modelo da Criação do Mundo em seis dias - parece situar o Futuro de fato como um 
"outro mundo", radicalmente distinto deste complexo de Presente-Passado que corresponde à aventura humana em direção à salvação ou à condenação. $\mathrm{O}$ Futuro corresponderá ao momento em que finalmente o tempo histórico poderá ser interrompido, tal como se interrompera o tempo da Criação naquele "sétimo dia" no qual Deus pudera finalmente descansar após o trabalho da Criação.

Figura 5 - O tempo linear cristão

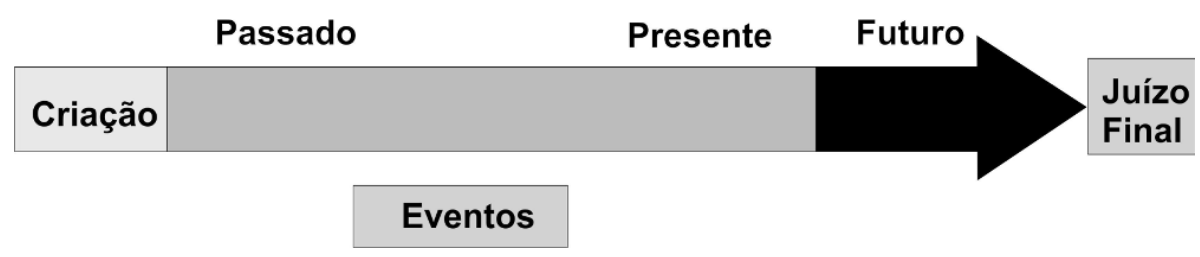

Fonte: Figura elaborada pelo autor.

A Figura 5 propõe um formato visual para sintetizar os principais traços do padrão de temporalidade proposto pelo modelo histórico-teológico do Cristianismo. O Tempo é linear e "teleológico", isto é, possui um "telos", um "fim" a ser atingido. ${ }^{35}$ Este tempo linear é enquadrado por duas datas: a da Criação e a do Juízo Final, e no seu decorrer é pontilhado por eventos que expressam a Vontade Deus. Já não importa tanto o número de etapas que constituem este percurso - as "seis idades do mundo" de Santo Agostinho ou as três épocas de Gioacchino da Fiore - mas sim o fato de que as diversas doutrinas das idades do mundo eram concebidas de tal modo que, depois do nascimento de Cristo, estava-se vivendo já a última delas, o que implicava que "desde então não poderia acontecer mais nada de novo, pois o mundo se encontrava sob a perspectiva do Juízo Final". ${ }^{36}$

A função dos eventos em tal estrutura de tempo é singular. Cada evento só adquire seu real sentido quando inserido e compreendido no interior desta sequência relacionada ao futuro teológico. ${ }^{37}$ Trata-se, de fato, de uma história "transcendente" - isto é, conduzida de fora pela vontade divina. ${ }^{38}$ No que concerne à Temporalidade - isto é, no que se refere à relação entre Passado, Presente e Futuro que se estabelece a partir da escatologia cristã - o Futuro constitui um outro mundo, distinto do Presente-Passado, embora este se conduza para aquele. Por fim, pode-se dizer que o tempo historiográfico do historiador-teólogo (isto é, o terceiro tempo que é produzido pela históriaconhecimento de um ponto de vista teológico-cristão) é reconstituído a partir de diversas histórias, que ilustram os vícios e virtudes e esclarecem a vontade de Deus. Posteriormente, e acompanhando a mesma linearidade e teleologia, os iluministas do século XVIII proporiam o seu ajuste: substituir pela "utopia sócio-política" a escatologia, substituir pelo "Reino da Razão" o Paraíso Prometido no final da linha, e introduzir no interior da linearidade teleológica, 
agora "imanente", um Espírito Absoluto, ao invés do Deus transcendente que intervém na História através de revelações e milagres inscritos nos eventos. Tal como assinala Koselleck em Passado Futuro, o projeto moderno do Iluminismo vê a história como uma marcha do Espírito Universal em direção à Liberdade. A História torna-se aqui, para retomar a expressão utilizada por Koselleck, um "singular coletivo", uma grande história da humanidade, e é sintomático que a palavra "História", no singular, substitua a expressão "Histórias", no plural, ainda muito utilizada no período da História Teológica pré-iluminista para designar a superposição de diversas histórias superpostas que foram se acumulando na experiência humana. Aqui, no entanto, já adentramos outro momento na história das formas do tempo, o qual mereceria um estudo especial.

\section{NOTAS}

1 "Esta gênese do mundo, cujo decurso narram as Musas, comporta o que vem antes e depois, mas não se estende por uma duração homogênea, por um tempo único. Ritmando este passado, não há uma 'cronologia', mas 'genealogia"” (VERNANT, Jean-Pierre. Aspectos míticos da memória e do tempo In: Mito e pensamento entre os gregos. São Paulo: Difusão Européia / EDUSP, 1973. p. 71-112).

2 Para um panorama sistemático e explicativo sobre a mitologia hindu e os significados de seus deuses, ver SAILEN, Debnath. The Meanings of Hindu Gods, Goddesses and Myths. Delhi: Rupa \& Co, 2009.

3 Para os hindus, existem os "anos do homem", os "anos do mundo" e os "anos de Brahma". Cada ano dos homens é um "dia do mundo". Ao mesmo tempo, atribui-se quatro idades para o mundo e que são chamadas mahayuga, durando cada qual 12.000 anos de mundo. Um mahayuga, portanto, dura 4.320000 anos do homem, já que no calendário hindu o ano é dividido em 360 dias. Seguindo adiante, mil mahayuga completos não são mais que um dia Brahma, sendo que uma noite de Brahma dura o mesmo tempo. Um dia e uma noite completa de Brahma é denominada kalpa, e constitui um ciclo completo para o universo desde sua criação até sua destruição.

4 Os Vedas - palavra que em sânscrito significa "conhecimento" - são formados por quatro grandes livros em sânscrito que constituem a base do sistema de escrituras sagradas do hinduísmo. Certas passagens do Rig Veda - o primeiro dos livros védicos - mencionam aspectos geográficos e culturais que têm permitido os estudiosos situarem a produção deste texto em Punjab entre 1700 e 1000a.C. Com relação ao seu conteúdo, os quatro livros dos vedas organizam-se em torno de mantras, os quais são suplementados por textos de apoio que se referem aos rituais sacrificiais nos quais esses mantras devem ser utilizados (os brâmanas) e também por textos que abordam aspectos filosóficos da tradição ritual, além de incluírem narrativas. Esta última categoria de textos de comentários, os Aranyakas e Upanixades, oferece respectivamente a base teológica e filosófica para compreender os Vedas e a mitologia hindu.

5 Duas boas edições do Rig Veda podem ser encontradas em: (1) MÜLLER, Friedrich Max. The Hymns of the Rigveda, with Sayana'a commentary. 6 vols. London: Trübner and co, 1849-1875; e (2) NOOTEN, B. van e HOLLAND. G. Rig Veda, a metrically restored text. Cambridge: Harvard University Press, 1994. Para uma exposição do Rig Veda em seu contexto, cfe: FRAWLEY, David. The Rig Veda and the History of India. Delhi: Aditya Prakashan, 2001. 
Sobre a literatura védica como um todo, cfe. GONDA, Jan. Vedic Literature (Samhitas and Brahmanas) - History of Indian Literature Wiesbaden: Otto Harassowitz, 1975.

6 Tales, embora nascido na cidade grega de Mileto, tinha ascendência fenícia - uma civilização que considerava como poderosas forças autônomas os elementos da natureza (Céu, Terra, Oceano, Sol, etc), honrando-os como deuses. Tales de Mileto readaptou estas noções no ambiente da filosofia jônica, a partir de uma sistemática observação que o levava a ver todos os elementos se transformando uns nos outros e que o conduziu à sua intuição fundamental de que todas as coisas, em última instância, correspondem a um só princípio (arché). Em seu sistema, a Água ocupou o lugar de elemento primordial. Os escritos de Tales não chegaram até nós, mas conhecemos suas ideias através de Diógenes Laércio, Simplício e Aristóteles, entre outros. Na Metafísica, Aristóteles assim se refere à proposição de Tales de que a "água" deveria ser considerada o elemento primordial: "Tales diz que o princípio de todas as coisas é a água, sendo talvez levado a formar essa opinião por ter observado que o alimento de todas as coisas é úmido e que o próprio calor é gerado e alimentado pela umidade. Ora, aquilo de que se originam todas as coisas é o princípio delas. Daí lhe veio essa opinião, e também a de que as sementes de todas as coisas são naturalmente úmidas e de ter origem na água a natureza das coisas úmidas" (ARISTOTELES. Metafísica. São Paulo: Abril, 1973. p. 216-7).

7 O conhecimento, nesta versão, é representado por Sarasvati, consorte da Brahma, que se manifesta a partir dele mesmo. Sobre a relação entre a consorte de Brahma e o conhecimento, ver (1) LUDVIK, Catherine. Sarasvati-Riverine Goddess of Knowledge: From the Manuscriptcarrying Vina-player to the Weapon-wielding Defender of the Dharma. Boston: Brill Academic Publishers, 2007; e também (2) NAGAR, Shantilal. Sarasvati: The Goddess of Learning and Wisdom. Delhi: BR Publishers. 2005. Sobre ver o papel do princípio feminino na mitologia hindu, em sentido mais amplo, ver KINSLEY, David. Hindu Goddesses: Vision of the Divine Feminine in the Hindu Religious Tradition. Berkeley: University of California, 1988.

8 Por outro lado, esta narrativa mítica também pode se ajustar a uma versão na qual Brahma brota do umbigo de um outro deus, chamado Vishnu.

9 Existe também a versão de que no início tudo era repouso e equilíbrio, e só Brahma existia. Houve então a primeira vibração - Om, o "som primordial" - a partir da qual o universo foi criado com o surgimento da trindade hindu formada por Brahma, Vishnu e Shiva. A partir daqui, entramos na sequência anterior. Sobre a idéia de um som sagrado criador na cosmogonia hindu, ver BECK, Guy L. Sonic Theology: Hinduism and Sacred Sound. Columbia: University of South Carolina Press, 1993.

${ }^{10}$ A consorte de Vishnu - ou seja, a sua shakti, ou aspecto feminino - é Lakshmi, deusa da prosperidade, da riqueza e da beleza.

${ }^{11}$ Em um dos mitos menores dentro do grande mito, Durga por duas vezes (em duas encarnações) desposou Shiva. O que também se conforma à natureza cíclica do mito.

${ }^{12}$ Estes três aspectos se desdobram de um deus ainda anterior: Adhinatha, o "imanifestado". Com relação à estrutura triádica da Criação no Rig Veda, ver KRAMRISCH, Stella. The Triple Structure of Creation in the Rig Veda. History of Religions, New York, v. 2, n. 1-2, p. 140-175, 1962-1963.

${ }^{13}$ A cosmogonia bramânica também pode se achar adaptada ao mito da decadência através das quatro "eras" do mundo. A idade da Terra, formando a Mahayuga, é dividida em quatro "eras" ou yugas. A cada Yuga que se passa, a virtude do mundo vai se perdendo progressivamente. Na Satya-Yuga a virtude prevalece e o mal é desconhecido; na Treta-Yuga a virtude cai para três quartos; na Dwapara-Yuga a virtude já caiu pela metade; na Kali-Yuga, por fim, só restará um quarto de virtude. Depois disto, virá a destruição renovadora, após a qual Brahma precisará 
recriar o mundo. Mais adiante, voltaremos a este padrão mítico, que concebe o mundo em termos de idades decaídas.

${ }^{14}$ SAHLINS, M. Metáforas históricas e realidades míticas. Rio de Janeiro: Zahar, 2008. p. 38.

${ }^{15}$ SAHLINS, M. História e cultura - apologias a Tucídides. Rio de Janeiro: Zahar, 2006. p. 87.

${ }^{16}$ Outro elemento cíclico é a presença dos Hecatônquiros, três gigantes que possuíam cem braços e cinquenta cabeças, e que eram filhos diletos de Gaia. Tanto Urano como Cronos cometeram o erro de os hostilizaram, e por isso atraíram a fúria de Gaia, que acabou conspirando para a sua deposição.

${ }^{17}$ A Teogonia de Hesíodo (final do século VIII a.C.) retrocede mais além na narrativa sobre a sucessão de gerações de deuses. O poeta conta que no início era o Caos, o "vazio primordial". Depois vieram Géia, a Terra, o Tártaro, deus das profundezas, e por fim Eros, a força do desejo e pai de toda a vida. O Caos deu origem a Érebo (escuridão profunda) e a Nix (a Noite). De Géia nasceram Urano (o Céu), Montes e Pontos (o Mar). A partir da união de Geia com seu filho Urano, entramos na sequência anterior. Ver BRANDÃO, Junito de Souza. Mitologia grega. Petrópolis: Vozes, 1986. p. 183.

${ }^{18}$ HESÍODO. Teogonia. Os trabalhos e dias. Lisboa: Imprensa Nacional, 2005. Para uma análise dos aspectos míticos na obra de Hesíodo, cfe. GRIFFIN, Jasper. Greek Myth and Hesiod. Oxford: Oxford University Press, 1986. Mais especificamente sobre a Teogonia, cfe. WEST, Martin L. Hesiod: Theogony. Oxford University Press, 1966.

${ }^{19} \mathrm{O}$ jainismo é uma religião indiana cuja fundação remete ao século VI a.C, na bacia do Gangis, e teria sido criada por Varnamana - um príncipe hindu que aos 28 anos decidiu abdicar de seus bens materiais para se dedicar à busca espiritual. A palavra "jina", que dá origem à designação jainismo, tem o significado de "conquistador". A base da religião jainista é a ideia de que cada ser humano está destinado a encarnar em sucessivos corpos, perfazendo um longo ciclo de reencarnações até atingir o estágio máximo de evolução, quando, então, a sequência de ciclos reencarnatórios cessa. Percebe-se. Desta forma, que ao nível das evoluções individuais o Jainismo também propõe a imagem do tempo cíclico de nascimento, vida e morte. Entrementes, conforme veremos a seguir, o jainismo também expressou a noção de tempo cíclico através de um grande mito cosmogônico que envolve sucessivas "eras" humanas.

${ }^{20}$ Sobre os jainistas e sua mitologia, ver DUNDAS, Paul; HINNELS, John (Orgs.). The Jains. London: Routledge, 2002. Mais especificamente sobre a cosmologia jainista, ver SCHUBRING, Walther. "Cosmography" In: BEURLEN, Wolfgang (Org.). The Doctrine of the Jainas. Delhi: Motilal Banarsidass Publ, 1995.

${ }^{21}$ Entre as funções do retorno mítico através do ritual, inclui-se também a função da cura. Adentrar o tempo mítico com vistas à purificação constitui, em diversas culturas, um dos caminhos para vencer ou superar enfermidades. Assim, não raramente o xamã, empenhado na cura de um indivíduo, recita o mito de origem da tribo ou mesmo a cosmogonia. A ideia é que a recriação do mundo pode curar o doente.

${ }^{22}$ Identificar-se ritualmente com o Deus, com o animal totêmico ou com o ancestral comum a toda a tribo é, além disso, assegurar a coesão do grupo e firmar a sua própria Identidade, por oposição a indivíduos pertencentes a outras culturas e que não partilham daquela tradição em comum. De igual maneira, recitar em ritual um mito cosmogônico é recriar o mundo mais uma vez, e portanto assegurar a manutenção do universo.

${ }^{23}$ SAHLINS, 2008, op. cit., p. 38. 
${ }^{24}$ ELIADE, Mircea. Cosmos e história: o mito do eterno retorno. São Paulo: Mercúrio, 1992.

${ }^{25}$ PATTARO, G. A Concepção Cristã do Tempo. In: RICOEUR, Paul (Org.). As culturas e o tempo: estudos reunidos pela UNESCO. Petrópolis: Vozes, 1975. p. 197-228.

${ }^{26}$ Vale ressaltar que, entre os Gregos Antigos, a ideia de um tempo linear aparece excepcionalmente em Epicuro e Lucrécio. Na Roma Antiga, Políbio também elabora no século II a.C uma abordagem da História que também insinua o tempo linear, pois pretende elaborar pela primeira vez uma História que é já universal (e não mais um múltiplo conjunto de várias histórias) ao organizar os acontecimentos em torno deste único processo que é a formação e expansão do domínio do Império Romano: “O caráter peculiar de nossa obra depende daquele que é o fato mais extraordinário de nossos tempos: dado que o destino volveu para uma única direção os acontecimentos de quase toda a terra habitada, e obrigou todos a se dobrarem para uma única finalidade, é necessário que o historiador recolha para os leitores, numa visão unitária do conjunto, os vários atos mediante os quais o acaso levou a cabo as coisas do mundo" (POLÍBIO, apud BODEI, Remo. A História tem um sentido? Bauru: EDUSC, 2001. p. 17). A história, com Políbio, passa a girar em torno da Missão de um Império universal.

${ }^{27}$ Com relação ao "monoteísmo profético", dos hebreus e cristãos, acrescenta Ernst Cassirer em seu estudo sobre A filosofia das formas simbólicas: "O Tempo torna-se Futuro, e somente Futuro. Passado e Presente perdem-se nesse Tempo do Futuro" (CASSIRER, Ernst. A Configuração do Tempo na consciência mítica e religiosa. In: A filosofia das formas simbólicas. Parte II: $O$ pensamento mítico. São Paulo: Martins Fontes, 2004. p. 212).

${ }^{28}$ KOSELLECK, Reinhart. Futuro passado - contribuição à semântica dos tempos históricos. Rio de Janeiro: Contraponto, 2006. p. 127.

${ }^{29}$ A “escatologia" corresponde à doutrina dos fins últimos, isto é, ao corpo de crenças relativas ao destino final do homem e do universo (LE GOFF, J. "Escatologia" In: DOMANO, Ruggiero (org.). Enciclopédia Einaudi. Lisboa: Imprensa Nacional - Casa da Moeda, 1984. p. 325). O "escatológico", desta maneira, refere-se a um "acontecimento final", de natureza religiosa.

${ }^{30}$ AGOSTINHO [Santo]. Elevações sobre os Mistérios. In: Confissões - Livro XI. Petrópolis: Vozes, 2005.

${ }^{31}$ Sobre as concepções de Joachim de Fiore, ver REEVES, Marjorie. Joachim of Fiore \& the prophetic future: a medieval study in historical thinking. Stroud: Sutton Pub., 1999.

32 BOSSUET, J-B. Discours sur l'histoire universelle, pour expliquer la suite de la religion et le changement des empires. Paris: Lamey, 1802.

${ }^{33}$ LESSING, Gotthold E. "Die Erziehung des Menschengeschlechts" [original: 1780]. In: LACHMANN, Karl; MUNCKER, Franz (Orgs). Sämtliche Werke (1886-1924). 16 vol. Berlin/ New York: Walter de Gruyter, 1979.

34 BODEI, Remo. A História tem um sentido? Bauru: EDUSC, 2001. p. 18.

35 "Telos" é a palavra grega que corresponde a "fim". "Teleológico" - algo que aponta para um fim pré-definido - não deve ser confundido com "Teológico", expressão que vem do radical "Teo", que se refere a "Deus". No caso da História Cristã, ocorre que ela seja simultaneamente Teológica (relacionada a Deus) e Teleológica (apontando para um “fim”).

${ }^{36}$ KOSELLECK, op. cit., p. 128.

37 "Tudo o que acontece sobre a Terra é passível de repetir-se, de um ponto de vista estrutural. Isso quer dizer que o acontecimento, tomado isoladamente, é ele mesmo dotado de importância. $\mathrm{O}$ acontecimento só se torna único e adquire seu sentido mais elevado quando é relacionado ao futuro teológico e ao Juízo Final. Ao atribuir à história um sentido para além de si mesma, 
Santo Agostinho conquista uma liberdade de interpretação para o fazer e o sofrer humanos, que lhe confere uma habilidade superior para enxergar de maneira especialmente precisa os acontecimentos terrenos" (KOSELLECK, op. cit., p. 127).

${ }^{38}$ Uma história "transcendente" opõe-se a uma "história imanente". A primeira é conduzida de fora, por uma vontade exterior como a de Deus; a segunda, que corresponde ao modelo de história que surge com o iluminismo, é "imanente" porque conduzida de dentro, pelos próprios homens que dela participam, e que, portanto, se tornam sujeitos de sua própria história.

Artigo recebido em maio de 2013. Aceito em novembro de 2013. 